\title{
Do Stemmed Tibial Components in Total Knee Arthroplasty Improve Outcomes in Patients With Obesity?
}

\author{
Sébastien Parratte MD, Matthieu Ollivier MD, Alexandre Lunebourg MD, \\ Nicolas Verdier MD, Jean Noel Argenson MD, PhD
}

Published online: 18 March 2016

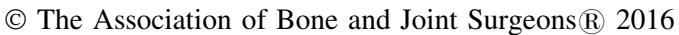

\begin{abstract}
Background Recent clinical studies have reported that patients with higher body mass index (BMI) are more likely to experience premature failure of total knee arthroplasty (TKA), lower knee scores, and perhaps more pain in the prosthetic joint. However, it is not known whether certain implant design features such as tibial stems might be associated with differences in the frequency of tibial pain in patients with higher BMIs.
\end{abstract}

Each author certifies that he or she, or a member of his or her immediate family, has no funding or commercial associations (eg, consultancies, stock ownership, equity interest, patent/licensing arrangements, etc) that might pose a conflict of interest in connection with the submitted article.

All ICMJE Conflict of Interest Forms for authors and Clinical Orthopaedics and Related Research ${ }^{\circledR}$ editors and board members are on file with the publication and can be viewed on request.

Clinical Orthopaedics and Related Research ${ }^{\mathbb{R}}$ neither advocates nor endorses the use of any treatment, drug, or device. Readers are encouraged to always seek additional information, including FDAapproval status, of any drug or device prior to clinical use.

Each author certifies that his or her institution approved the human protocol for this investigation, that all investigations were conducted in conformity with ethical principles of research, and that informed consent for participation in the study was obtained.

This work was performed at the Institute for Locomotion, AixMarseille University, Marseille, France.

S. Parratte $(\bowtie)$, M. Ollivier, A. Lunebourg, N. Verdier, J. N. Argenson

Department of Orthopaedic Surgery, APHM, Institute for Locomotion, Sainte-Marguerite Hospital, 13009 Marseille,

France

e-mail: sebastien@parratte.fr

S. Parratte, M. Ollivier, A. Lunebourg, N. Verdier, J. N. Argenson

Aix-Marseille University, CNRS, Marseille, France
Questions/purposes Therefore, it was our aim to compare (1) function and pain (as measured by the New Knee Society Score, Knee Injury and Osteoarthritis Outcome Score [KOOS], and visual analog pain scores); (2) quality of life (as measured by SF-12); and (3) mechanical complications and premature revision (defined as revision before 2 years) between patients with obesity undergoing TKA $\left(\right.$ BMI $>30 \mathrm{~kg} / \mathrm{m}^{2}$ ) who received either a stemmed or an unstemmed tibial component.

Methods In this randomized controlled trial, 120 patients with a BMI $>30 \mathrm{~kg} / \mathrm{m}^{2}$ scheduled for primary arthritis TKAs and end-stage knee osteoarthritis were included. Patients were stratified into groups defined as moderately obese (BMI 30-35 kg/m², $\mathrm{N}=60$ ) and severely obese (BMI $>35 \mathrm{~kg} / \mathrm{m}^{2}, \mathrm{~N}=60$ ) groups. Patients in each stratified subgroup then were randomized to receive either a stemmed $(10 \mathrm{~mm} / 100 \mathrm{~mm})$ proximally cemented tibial component or the other, a standard cemented component. Patients were evaluated preoperatively and 2 years after surgery using the new Knee Society Score (KSS), KOOS, SF-12 score, and a visual analog pain score after 100 meters of walking. Although no minimum clinically important differences (MCIDs) have yet been defined for the new KSS, we considered differences smaller than 10 points to be unlikely to be clinically important; the MCID for the KOOS is estimated at 8 to 10 points, the SF-12 to be 4 points, and the visual analog scale to be $2 \mathrm{~cm}$ on a $10-\mathrm{cm}$ scale. Patients were followed until death, revision, or for a minimum of 2 years (mean, $3 \pm 0.8$ years; range, 2-4 years). No patient was lost to followup before 2 years.

Results Although we found that patients treated with stemmed TKAs had higher functional outcomes, the differences were small and unlikely to be clinically important (subjective KSS mean $69 \pm 7$ points versus $75 \pm 7$, mean difference 6 points, $95 \%$ confidence interval $[\mathrm{CI}] 2-11, \mathrm{p}=$ 
0.03; objective KSS mean $80 \pm 6$ points versus $85 \pm 6$ points, mean difference 5 points, 95\% CI 0-9, p = 0.01). Compared with patients with a stemmed TKA, patients with a standard implant reported lower KOOS pain subscores $(81 \pm 9$ versus $76 \pm 8 ; \mathrm{p}=0.04)$ and lower KOOS symptom subscores $(74 \pm 7$ versus $68 \pm 7 ; \mathrm{p}=0.03)$. The proportions of patients experiencing complications were not different with the numbers available for all groups and subgroups.

Conclusions Although we detected differences in some patient-reported outcomes scores for pain and function favoring implants with stems, the differences were small and unlikely to be clinically important. Because these stems may have disadvantages, perhaps including difficulty of revision, we cannot draw a strong conclusion in support of their use.

Level of Evidence Level I, therapeutic study.

\section{Introduction}

The prevalence of primary and revision total TKAs performed worldwide has increased over the last decades and this demand for knee arthroplasty is expected to further grow in the upcoming years [13]. Simultaneously, the prevalence of obesity has dramatically increased worldwide over the last three decades [14, 25, 29]. In 2014, the Global Health Observatory estimated $13 \%$ of the world's population is obese [29]. Worldwide, 3 million people die every year from the complications of obesity. This rise was particularly pronounced in the United States with today more than two in three adults being overweight or obese. Obesity also increased in several European countries over the past two decades. Thus, the growth in the proportion of the population with obesity combined with an increased demand for TKA will lead to an increased number of patients with obesity requesting TKA [20, 27].

Although many studies have suggested that patients with obesity do well with TKA $[11,14,17]$, others have suggested that this group is at risk for a variety of complications [6, 11, 14, 17]. Studies have disagreed about whether obesity results in lower scores for pain and function [4], but much of the recent evidence suggests that it may indeed be a risk factor for persistent pain and lower levels of function after TKA [6, 11, 14, 17]. One recent study concluded that consideration should be given to additional tibial fixation in patients with obesity [1]. Therefore, it seems important to see whether there are any implant-related choices that can improve the likelihood that a patient with obesity will achieve high scores for function and quality of life after TKA. Stems on tibial components may limit the micromotion and improve the load distribution, particularly on patients with obesity [23], so stemmed tibial components may represent one such choice $[1,6,23]$. Based on our clinical experience [2] and the results of those other studies $[1,6,23]$, we hypothesized that a stemmed tibial component would improve patientreported outcomes for function and quality of life after TKA in patients with obesity. Because particular complications such as intraoperative fractures have been described in patients treated with stemmed components [7], we felt it important also to investigate potential drawbacks of stemmed tibial components as well.

Therefore, it was our aim to compare (1) function and pain (as measured by the New Knee Society Score, Knee Injury and Osteoarthritis Outcome Score [KOOS], and visual analog pain scores); (2) quality of life (as measured by SF-12); and (3) mechanical complications and premature revision (defined as revision before 2 years) between patients with obesity undergoing TKA (body mass index $[\mathrm{BMI}]>30 \mathrm{~kg} / \mathrm{m}^{2}$ ) who received either a stemmed or an unstemmed tibial component.

\section{Patients and Methods}

After institutional review board approval, we conducted a randomized clinical trial from January 2010 to December 2011. The sample size of the study was calculated to be 23 patients in each of the four arms of the trial to provide $80 \%$ power to detect a difference in Knee Society Score (KSS) $>4$ points (expected postoperative objective KSS $88 \pm 3$ points, subjective KSS $69 \pm 6$ points [9]) between two of the four groups $(\alpha=0.05, \beta=0.20)$.

The inclusion criteria were: BMI $>30 \mathrm{~kg} / \mathrm{m}^{2}$ with age $>$ 20 years and $<85$ years and candidates for unilateral primary TKA as treatment of end-stage knee disease secondary to degenerative or posttraumatic arthritis. The exclusion criteria included: age $<20$ years or $>85$ years; severe deformity with $>15^{\circ}$ of varus, valgus, or fixed flexion deformity; a history of infection; severe neurological or musculoskeletal disorders; any congenital, developmental, or other bone disease; or previous surgery that may adversely affect postoperative outcomes.

One hundred eighty-one patients met the inclusion criteria and were assessed for eligibility during the study period. During the study period, a total of 455 primary TKAs were performed by the two operative surgeons (JNA, SP). Patients who agreed to participate in the study completed written informed consent. One hundred twenty patients were then prospectively enrolled, paired on age $( \pm$ 5 years) and gender, and stratified into two groups based on their BMI status in a moderately obese patient group $(\mathrm{n}=$ $60)$ and in a severely obese patient group $(n=60)$ 
according to the World Health Organization definition. In each group, patients were then randomized into two subgroups: (1) traditional cemented tibial tray (standard subgroup $n=30$ patients); or (2) cemented stemmed tibial tray (stem subgroup $\mathrm{n}=30$ patients) (Fig. 1). Stratified randomization was performed using a computer program to dynamically balance the study groups on the basis of the patient's age and sex.

The final study group comprised 120 patients including 68 women and 52 men with a mean age of $68 \pm 9$ years (range, 41-85 years). The mean BMI was $36 \pm 4 \mathrm{~kg} / \mathrm{m}^{2}$ (range, 30-44 kg/m²) (Table 1). Patients' bone mass density (BMD) was measured using dual-energy $\mathrm{x}$-ray absorptiometry (IDXA; GE Medical Systems, Milwaukee,
WI, USA) at the hip and the spine. The standard analysis recommended by the manufacturer was performed preoperatively on all patients, before surgery, to evaluated bone density status. Following the World Health Organization definition, patients were considered as osteoporotic when the $\mathrm{T}$-score was $\geq 2.5$ and osteopenic for a $\mathrm{T}$-score $>1$ [30].

Two surgeons with subspecialty training and interest in TKA (JNA, SP) performed all the surgeries. NexGen LPS Flex (Zimmer, Warsaw, IN, USA) posterior-stabilized femoral components and NexGen all-polyethylene patella components were cemented in all patients. The tibial components used in this study were the NexGen modular tibial tray without a stem in the standard groups (Fig. 2A)

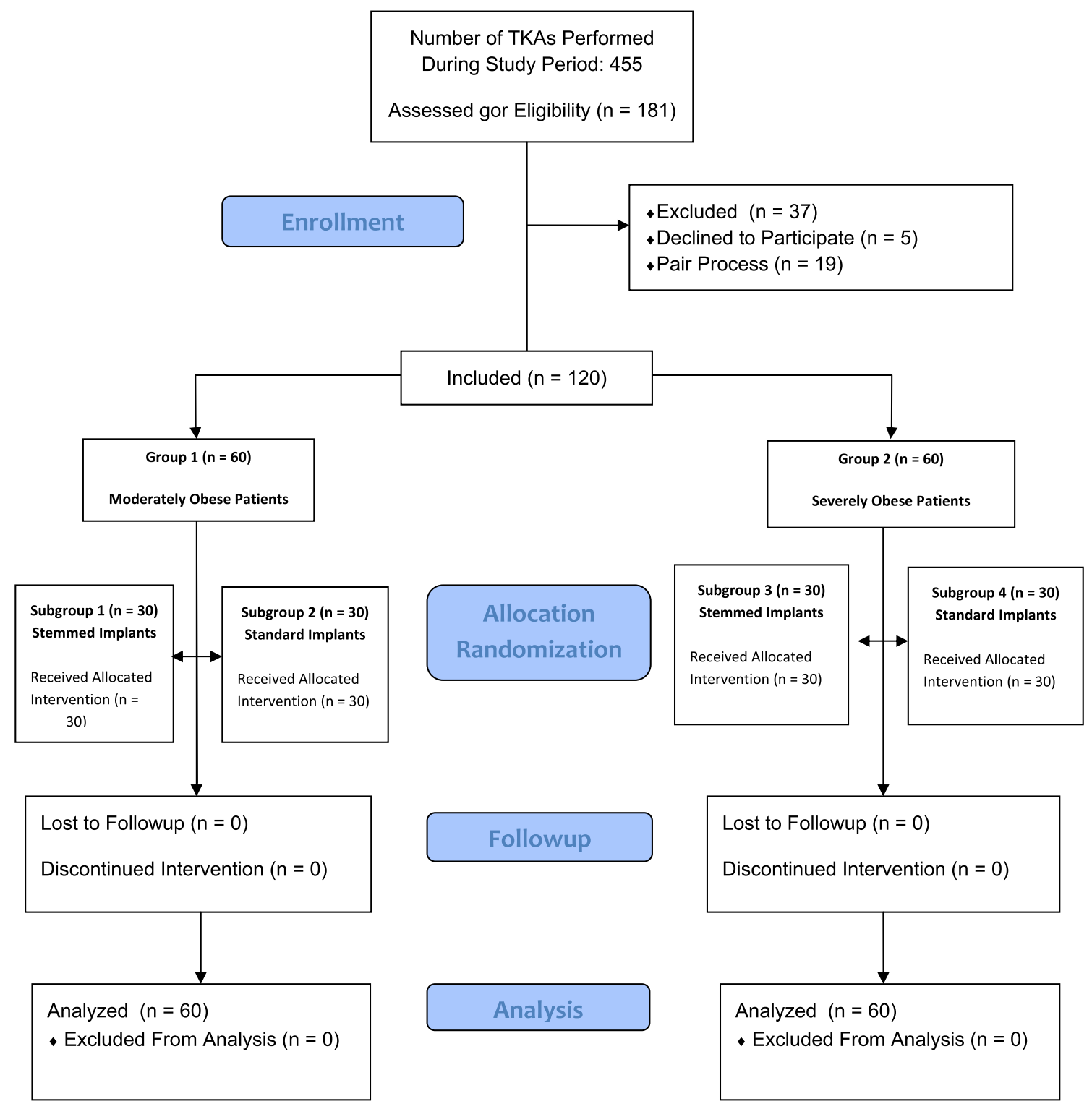

Fig. 1 A flow diagram illustrates patient enrollment, allocation, followup, and analysis. 
and with a stem in the stem groups. The stem used was a 10-mm/100-mm long cemented stem (Fig. 2B). No crossover after randomization occurred among the study groups.

All TKAs were done without a tourniquet using a standard paramedian incision, a subvastus surgical approach, and tibial resection with an extramedullary guide, distal femoral resection with an intramedullary guide, and femoral rotation set according to a previously described technique [24]. Intravenous antibiotic prophylaxis, mechanical and chemical prophylaxis for thromboembolic disease, antibiotics within the bone cement, and wound drains were used systematically for 24 hours after surgery. A comprehensive multimodal anesthesia and analgesia program based on peripheral nerve blocks was used in all groups. Structured physical therapy began with patients moved from the bed to the chair the day of surgery, progressed to walking weightbearing as tolerated the day after surgery, and culminated with stairclimbing on Day 2. Study endpoints were compared at followup 2 years after surgery.

To answer our questions about function and pain, we compared scores on the new KSS [11], the KOOS [18, 21], and the visual analog scale (VAS) pain at 2 years between the patients with a stemmed tibial component and the patients without a stem. The objective component of the new KSS was used in our study (corresponds to the previous version of the "knee" score but the "pain" item has
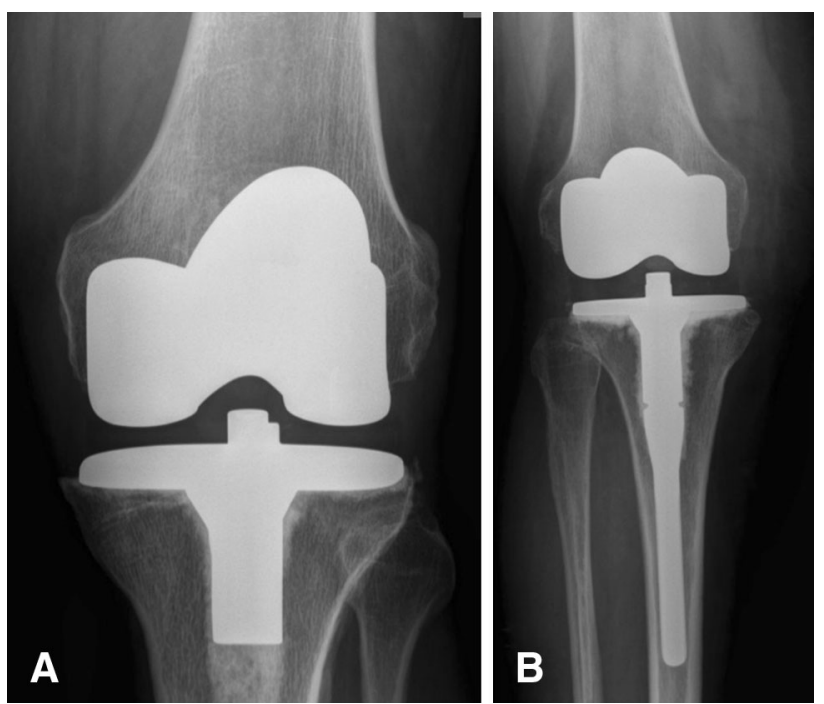

Fig. 2A-B Shown are an AP radiograph of a standard TKA at 2 years followup (A) and an AP radiograph of a stemmed TKA at 2 years followup $(\mathbf{B})$.

Table 1. Results of demographic parameters and preoperative functional status analysis (multiple analysis of variance)

\begin{tabular}{|c|c|c|c|c|c|}
\hline \multirow[b]{2}{*}{ Parameters of interest } & \multicolumn{2}{|c|}{ Moderately obese } & \multicolumn{2}{|c|}{ Severely obese } & \multirow[t]{2}{*}{$\mathrm{p}$ value } \\
\hline & Stem & No stem & Stem & No stem & \\
\hline \multicolumn{6}{|l|}{ Demographics } \\
\hline \multirow[t]{2}{*}{ Sex (female/male) } & $35 / 25$ & & $35 / 25$ & & 0.7 \\
\hline & $17 / 13$ & $18 / 12$ & $17 / 13$ & $18 / 12$ & 0.7 \\
\hline \multirow[t]{2}{*}{ Age at surgery (years) } & $68 \pm 9$ & & $69 \pm 8$ & & 0.3 \\
\hline & $67 \pm 11$ & $69 \pm 7$ & $69 \pm 9$ & $68 \pm 7$ & 0.4 \\
\hline \multirow[t]{2}{*}{ BMI $\left(\mathrm{kg} / \mathrm{m}^{2}\right)$} & $33 \pm 1$ & & $38 \pm 2(3$ & & 0.0001 \\
\hline & $32 \pm 1$ & $33 \pm 2$ & $39 \pm 2$ & $38 \pm 2$ & $0.0001 *$ \\
\hline \multicolumn{6}{|c|}{ Preoperative function (points) } \\
\hline \multirow[t]{2}{*}{ Subjective KSS } & $45 \pm 12$ & & $46 \pm 13$ & & 0.3 \\
\hline & $47 \pm 12$ & $44 \pm 12$ & $47 \pm 12$ & $46 \pm 14$ & 0.1 \\
\hline \multirow[t]{2}{*}{ Objective KSS } & $33 \pm 11$ & & $36 \pm 10$ & & 0.1 \\
\hline & $34 \pm 11$ & $32 \pm 12$ & $36 \pm 12.3$ & $34 \pm 13$ & 0.09 \\
\hline \multirow[t]{2}{*}{ SF-12 physical } & $39 \pm 8$ & & $37 \pm 9$ & & 0.2 \\
\hline & $38 \pm 7$ & $40 \pm 8$ & $38 \pm 10$ & $37 \pm 8$ & 0.08 \\
\hline \multirow[t]{2}{*}{ SF-12 mental } & $42 \pm 12$ & & $40 \pm 12$ & & 0.1 \\
\hline & $44 \pm 12$ & $41 \pm 11$ & $41 \pm 13$ & $38 \pm 12$ & 0.07 \\
\hline \multirow[t]{2}{*}{ Pain (VAS) } & $6 \pm 3(2$ & & $6 \pm 4(2-$ & & 0.3 \\
\hline & $5 \pm 3$ & $6 \pm 3$ & $6 \pm 4$ & $6 \pm 4$ & 0.1 \\
\hline \multirow[t]{2}{*}{ Preoperative HKA $\left(^{\circ}\right)$} & $180 \pm 2$ & & $180 \pm 2$ & & 0.6 \\
\hline & $180 \pm 2$ & $180 \pm 2$ & $179 \pm 2$ & $179 \pm 2$ & 0.5 \\
\hline
\end{tabular}

Groups values are mean \pm SD and range (minimum-maximum); subgroup values are mean $\pm \mathrm{SD}$; *a pairwise comparison showed no differences between BMI for Subgroups 1-2 ( $\mathrm{p}=0.3)$ and Subgroups 3-4 $(\mathrm{p}=0.4)$; BMI = body mass index; KSS = Knee Society Score; VAS = visual analog scale; HKA = hip-knee angle. 
Table 2. Comparison of preoperative and postoperative functional scores between groups and subgroups

\begin{tabular}{|c|c|c|c|c|c|c|c|c|c|c|}
\hline Group & $\begin{array}{l}\text { Subjective KSS } \\
\text { preoperative }\end{array}$ & $\begin{array}{l}\text { Subjective } \\
\text { KSS } \\
2 \text { years }\end{array}$ & $\begin{array}{l}\text { Objective } \\
\text { KSS } \\
\text { preoperative }\end{array}$ & $\begin{array}{l}\text { Objective } \\
\text { KSS } \\
2 \text { years }\end{array}$ & $\begin{array}{l}\text { SF-12 physical } \\
\text { preoperative }\end{array}$ & $\begin{array}{l}\text { SF-12 } \\
\text { physical } \\
2 \text { years }\end{array}$ & $\begin{array}{l}\text { SF-12 } \\
\text { mental } \\
\text { preoperative }\end{array}$ & $\begin{array}{l}\text { SF-12 } \\
\text { mental } \\
2 \text { years }\end{array}$ & $\begin{array}{l}\text { VAS } \\
\text { preoperative }\end{array}$ & $\begin{array}{l}\text { VAS } \\
2 \text { years }\end{array}$ \\
\hline $\begin{array}{l}\text { Moderately } \\
\text { obese }\end{array}$ & $45 \pm 13$ & $74 \pm 8^{*}$ & $33 \pm 12$ & $83 \pm 6^{*}$ & $39 \pm 9$ & $68 \pm 10^{*}$ & $42 \pm 13$ & $58 \pm 10^{*}$ & $6 \pm 4$ & $2 \pm 3^{*}$ \\
\hline Stem & $47 \pm 12$ & $75 \pm 7 *$ & $34 \pm 11$ & $84 \pm 5^{*}$ & $38 \pm 7$ & $69 \pm 10^{*}$ & $44 \pm 12$ & $58 \pm 9 *$ & $5 \pm 3$ & $2 \pm 3^{*}$ \\
\hline No Stem & $44 \pm 12$ & $72 \pm 6^{*}$ & $32 \pm 12$ & $82 \pm 5^{*}$ & $40 \pm 8$ & $68 \pm 9^{*}$ & $41 \pm 11$ & $59 \pm 10^{*}$ & $6 \pm 3$ & $3 \pm 2 *$ \\
\hline $\begin{array}{c}\text { Severely } \\
\text { obese }\end{array}$ & $46 \pm 14$ & $70 \pm 9 *$ & $36 \pm 14$ & $82 \pm 8^{*}$ & $37 \pm 10$ & $66 \pm 12 *$ & $40 \pm 13$ & $56 \pm 10^{*}$ & $6 \pm 5$ & $3 \pm 3^{*}$ \\
\hline Stem & $47 \pm 12$ & $74 \pm 6^{*}$ & $36 \pm 12$ & $84 \pm 6^{*}$ & $38 \pm 10$ & $67 \pm 10^{*}$ & $41 \pm 13$ & $57 \pm 10^{*}$ & $6 \pm 4$ & $2 \pm 3^{*}$ \\
\hline No Stem & $46 \pm 14$ & $66 \pm 5^{*}$ & $34 \pm 13$ & $78 \pm 6^{*}$ & $37 \pm 8$ & $66 \pm 12 *$ & $40 \pm 12$ & $56 \pm 8 *$ & $6 \pm 4$ & $4 \pm 3^{*}$ \\
\hline
\end{tabular}

Values are mean $\pm \mathrm{SD}$; *difference between preoperative and postoperative values $\mathrm{p}<0.0001 ; \mathrm{KSS}=$ Knee Society Score; VAS $=$ visual analog scale.

been improved by replacing it with a "symptoms" item) as well as the subjective component evaluating functional activity (a self-evaluation questionnaire score on 100 points with 100 as the best score). The patients were asked to fill the KOOS as described during the validation of this score with 100 as the highest score for each subscale of the score (pain, symptoms, activity of the daily living, sport, quality of life) [28]. Concerning pain, patients were asked to score the pain during a 100-meter walk in an area defined between the joint line and $5 \mathrm{~cm}$ below marked on the patient's skin using a dedicated pen and measured using the VAS [6]. Pain at the tip of the stem (in an area defined from $5 \mathrm{~cm}$ below the joint line to $15 \mathrm{~cm}$ below the joint line) was also evaluated in the stemmed TKA subgroups. The quality of life at last followup was compared between the groups using and the SF-12 Health Survey. Finally, mechanical complications were compared among the different subgroups of patients; for this, we included fractures around the stem, tibial revision for any reason, or progressive radiolucencies under the tibial plateau. To do so, postoperative radiographs at last followup including standing weightbearing short AP films, lateral, and Merchant views of the knee were performed in the same center according to the same protocol. Radiographic assessment was performed following the Knee Society Total Knee Arthroplasty Roentgenographic Evaluation and Scoring System [10] including an analysis of the tibial component angle and of the global frontal alignment measured on fulllength radiographs. Tibial radiolucencies were also analyzed for all patients.

Although no minimum clinically important differences (MCIDs) have yet been defined for the new KSS, we considered differences smaller than 10 points to be unlikely to be clinically important; the MCID for the KOOS is estimated at 8 to 10 points, the SF-12 to be 4 points, and the VAS to be $2 \mathrm{~cm}$ on a $10-\mathrm{cm}$ scale [8].
Patients were followed until death, revision, or for a minimum of 2 years (mean, $3 \pm 0.8$ years; range, $2-4$ years). No patient was lost to followup before 2 years (Table 2). The patients and surgeons were both blinded with regard to the group assignment before surgery.

\section{Statistical Analysis}

Data are summarized and reported using means (SD) for variables comprised of continuous data and count (percent) for categorical data. The analysis focused on comparing subjects in the two study groups: moderately obese (Group 1) and severely obese (Group 2), and in the four study subgroups: moderately obese with stemmed implant, moderately obese standard with implant group, severely obese stemmed implant group, and severely obese with standard implant group. All analyses were performed based on the intent-to-treat principle in which subjects were analyzed according to the study groups and subgroups in which they were randomized. The primary analysis focused on potential differences in terms of functional results between groups and subgroups using both univariate and multivariate statistical methods. A secondary analysis was performed focusing on patients' (1) functional scores regarding gender, BMD status (osteopenia with $\mathrm{T}$-score $<-1$ or "normal" BMD with T-score $>1$, postoperative lower limb alignment, and tibial implant positioning; and (2) postoperative pain improvement (VAS improvement > 2) defined as "postoperative condition" and type of implant (stemmed versus standard), gender (male versus female), and BMD status (osteopenia versus normal) defining exposure status in an "exposed-unexposed" analysis.

Outcomes based on continuous data (such as functional scores) were compared using multiple analyses of variance. 
Categorical outcomes (including BMD status) were compared using chi-square tests or Fisher's exact tests associated with dedicated odds ratio. All statistical tests were two-sided and $\mathrm{p}$ values 0.05 were considered significant. All analysis was conducted using IBM SPSS Statistic 22.0 (IBM Corporation, Somers, NY, USA).

All patients provided written consent and the study received authorization from our local ethics committee.

\section{Results}

Although we found that patients treated with stemmed TKAs had higher functional outcomes, the differences were small and unlikely to be clinically important (subjective KSS mean $69 \pm 7$ points versus $75 \pm 7$, mean difference 6 points, 95\% confidence interval [CI] 2-8, p = 0.03; objective KSS mean $80 \pm 6$ points versus $85 \pm 6$ points, mean difference 5 points, $95 \%$ CI $0-7, \mathrm{p}=0.01$; Table 3). Compared with patients with a stemmed TKA, patients with a standard implant reported lower KOOS pain subscores ( $81 \pm 9$ versus $76 \pm 8$, mean difference 5 points, $95 \%$ CI $0-10, p=0.04$ ) and lower KOOS symptom subscore $(74 \pm 7$ versus $68 \pm 7$, mean difference 6 points, 95\% CI 1-11, p = 0.03; Fig. 3). Having a stemmed TKA on osteopenic bone was associated with greater improvements in pain, defined as a VAS score improvement of greater than 2 points out of $10(80 \%$ versus $61 \%$, odds ratio [OR], 2.49; 95\% CI, 1.1-5.65; $\mathrm{p}=0.03)$. After controlling for potentially confounding variables such age, gender, and implant positioning, we found that being a woman, not having a stemmed TKA, and having a T-score $<-1$ were independently and negatively associated with postoperative functional scores (Table 4).

No differences were found with the numbers available in terms of quality-of-life scores between groups or subgroups at a minimum followup of 2 years. SF-12 scores were not different with the numbers available for patients in the stemmed TKA subgroups (mean physical score: $68 \pm 11$ points/mental score $58 \pm 12$ points) and standard TKA subgroups (mean physical score: $67 \pm 12$ points/mental score: $57 \pm 11$; all $\mathrm{p}>0.05$ ).

With the numbers available, there were no differences between the groups treated with or without stems in terms of surgical complications (12\% [seven of 60] versus $13 \%$ [eight of 60]; OR, 0.86; 95\% CI, 0.2-2.5; p = 0.9; Table 5). Two knees were revised: one for an acute deep infection 32 months after TKA that healed after open débridementpolyethylene exchange and antibiotic treatment for 6 weeks. The second patient was a patient with severe obesity with a standard implant who was reoperated on for aseptic loosening of the tibial implant 28 months after a standard TKA.

\section{Discussion}

As obesity is becoming more prevalent, the proportion of patients undergoing TKA who are obese is expected to rise. Lower functional scores after TKA have been

Table 3. Results of postoperative functional status analysis (multiple analysis of variance)

\begin{tabular}{|c|c|c|c|c|c|}
\hline \multirow[b]{2}{*}{$\begin{array}{l}\text { Postoperative } \\
\text { outcomes }\end{array}$} & \multicolumn{2}{|c|}{$\begin{array}{l}\text { Moderately obese } \\
30<\mathrm{BMI}<35 \mathrm{~kg} / \mathrm{m}^{2}\end{array}$} & \multicolumn{2}{|c|}{$\begin{array}{l}\text { Severely obese } \\
\text { Group } 2 \text { BMI }>35 \mathrm{~kg} / \mathrm{m}^{2}\end{array}$} & \multirow[t]{2}{*}{$\mathrm{p}$ value } \\
\hline & Stemmed TKA & Standard TKA & Stemmed TKA & Standard TKA & \\
\hline \multirow[t]{2}{*}{ Subjective KSS } & $74 \pm 8$ & & $70 \pm 9$ & & NS \\
\hline & $75 \pm 7$ & $72 \pm 6$ & $74 \pm 6$ & $66 \pm 5$ & $0.001 *$ \\
\hline \multirow[t]{2}{*}{ Objective KSS } & $83 \pm 6$ & & $82 \pm 8$ & & N.S \\
\hline & $84 \pm 5$ & $82 \pm 5$ & $85 \pm 6$ & $78 \pm 6$ & $0.01^{\dagger}$ \\
\hline \multirow[t]{2}{*}{ SF-12 physical } & $69 \pm 9$ & & $66 \pm 12$ & & NS \\
\hline & $69 \pm 10$ & $68 \pm 9$ & $67 \pm 10$ & $65 \pm 112$ & NS \\
\hline \multirow[t]{2}{*}{ SF-12 mental } & $58 \pm 9$ & & $56 \pm 9$ & & NS \\
\hline & $58 \pm 9$ & $59 \pm 10$ & $57 \pm 10$ & $56 \pm 8$ & NS \\
\hline \multirow[t]{2}{*}{ Pain (VAS) } & $2 \pm 3$ & & $3 \pm 3$ & & NS \\
\hline & $2 \pm 3$ & $3 \pm 2$ & $2 \pm 3$ & $4 \pm 3$ & $0.04^{*}$ \\
\hline
\end{tabular}

Values are mean $\pm \mathrm{SD} ; *$ a pairwise comparison showed that the only differences occurred at severely obese with stemmed TKA versus Severely obese with standard TKA $(\mathrm{p}=0.006) ;{ }^{\dagger}$ a pairwise comparison showed that the only differences occurred at obese with stemmed TKA versus severely obese with standard TKA $(\mathrm{p}=0.009) ;{ }^{*}$ a pairwise comparison showed that the only differences occurred at obese with stemmed TKA versus Severely obese with standard TKA $(\mathrm{p}=0.02)$; BMI = body mass index; KSS = Knee Society Score; VAS = visual analog scale; NS = nonsignificant. 


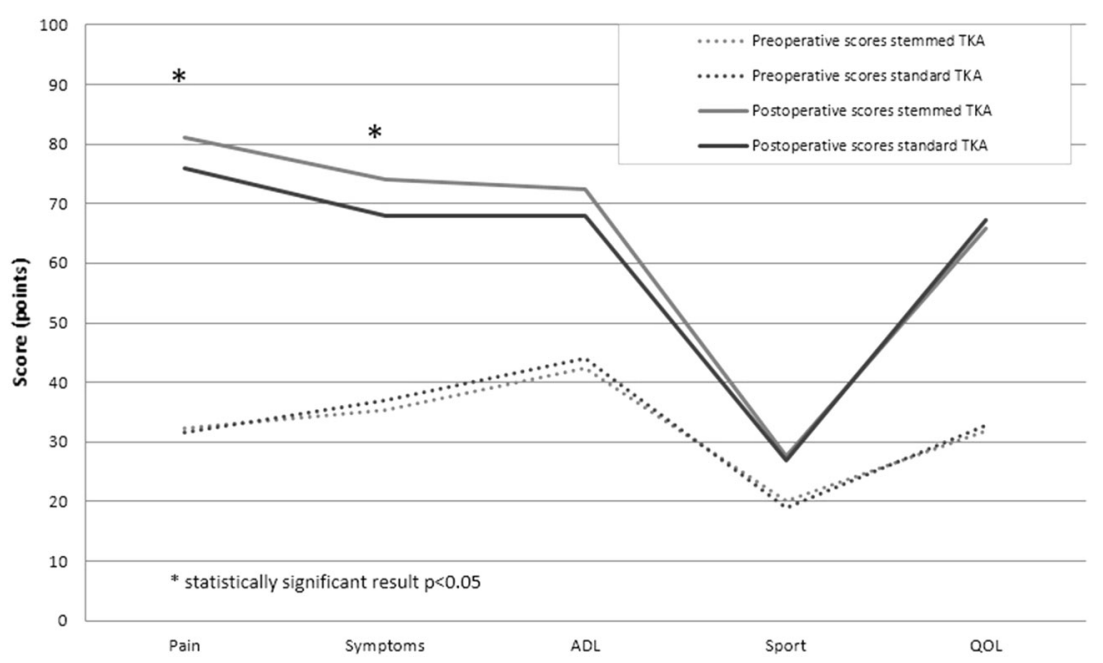

Fig. 3 The preoperative and postoperative mean KOOS for patients enrolled in stemmed and standard TKA subgroups is shown. ADL = activities of daily living; QOL = quality of life.

Table 4. Results of demographic parameters and implant type and implant positioning on postoperative functional scores (multiple analysis of variance)

\begin{tabular}{|c|c|c|c|c|c|c|c|c|c|c|}
\hline $\begin{array}{l}\text { Parameters included in the } \\
\text { multivariate analysis }\end{array}$ & $\begin{array}{l}\text { Subjective } \\
\text { KSS }\end{array}$ & $\begin{array}{l}\text { Objective } \\
\text { KSS }\end{array}$ & $\begin{array}{l}\text { SF-12 } \\
\text { physical }\end{array}$ & $\begin{array}{l}\text { SF-12 } \\
\text { mental }\end{array}$ & $\begin{array}{l}\text { KOOS } \\
\text { pain }\end{array}$ & $\begin{array}{l}\text { KOOS } \\
\text { symptoms }\end{array}$ & $\begin{array}{l}\text { KOOS } \\
\text { ADL }\end{array}$ & $\begin{array}{l}\text { KOOS } \\
\text { Sport }\end{array}$ & $\begin{array}{l}\text { KOOS } \\
\text { QOL }\end{array}$ & VAS \\
\hline Gender (female) & $0.007^{*}$ & $0.01 *$ & 0.06 & 0.07 & $0.02 *$ & $0.01 *$ & $0.02 *$ & 0.3 & 0.08 & $0.04 *$ \\
\hline Age & 0.08 & 0.1 & 0.07 & 0.09 & 0.2 & 0.1 & 0.2 & 0.2 & 0.3 & 0.3 \\
\hline BMI & 0.07 & 0.1 & 0.07 & 0.06 & 0.3 & 0.2 & 0.09 & 0.1 & 0.2 & 0.4 \\
\hline $\mathrm{BMD}<-1$ & $0.03 *$ & $0.04 *$ & $0.04 *$ & 0.07 & $0.04 *$ & 0.07 & 0.06 & 0.2 & 0.2 & $0.03 *$ \\
\hline Implant type & $0.02 *$ & $0.01 *$ & 0.08 & 0.06 & 0.03 & 0.03 & 0.05 & 0.1 & 0.1 & $0.02 *$ \\
\hline Preoperative HKA & 0.3 & 0.4 & 0.5 & 0.5 & 0.3 & 0.3 & 0.5 & 0.4 & 0.6 & 0.7 \\
\hline Postoperative HKA & 0.4 & 0.2 & 0.4 & 0.6 & 0.6 & 0.4 & 0.6 & 0.5 & 0.3 & 0.6 \\
\hline$\beta$ angle & 0.5 & 0.3 & 0.3 & 0.6 & 0.5 & 0.4 & 0.7 & 0.7 & 0.6 & 0.7 \\
\hline$\alpha$ angle & 0.4 & 0.5 & 0.6 & 0.5 & 0.4 & 0.3 & 0.5 & 0.6 & 0.7 & 0.6 \\
\hline
\end{tabular}

Values are mean $\pm \mathrm{SD}$; *statistically significant relationship; KSS = Knee Society Score; KOOS = Knee Injury and Osteoarthritis Outcome Score; $\mathrm{ADL}=$ activities of daily living; $\mathrm{QOL}=$ quality of life; VAS = visual analog scale; $\mathrm{BMI}=$ body mass index; HKA = hip-knee angle; $\beta$ angle $=$ tibial implant frontal mechanical axis; $\alpha$ angle $=$ tibial implant lateral mechanical axis .

observed as well as a twofold greater risk of aseptic tibial failures for patients with a BMI of $\geq 35 \mathrm{~kg} / \mathrm{m}^{2}$ [1]. Recent studies concluded that consideration should be given to additional tibial fixation in patients with obesity [1]. Based on our clinical experience [2] and the results of recent studies $[1,6,23]$ we hypothesized that a stemmed tibial component would improve function, patient-reported outcomes, and reduce complications after TKA in patients with obesity. Therefore, it was our aim to compare (1) function and pain (as measured by the new KSS, KOOS, and VAS pain scores); (2) quality of life (as measured by SF-12); and (3) mechanical complications and premature revision (defined as revision before 2 years) between patients with obesity undergoing TKA (BMI $>30 \mathrm{~kg} / \mathrm{m}^{2}$ ) who received either a stemmed or an unstemmed tibial Although some differences in pain and function were found in favor of stemmed tibial components, in many other important areas, we found no such differences; and, importantly, the observed differences were small in magnitude and so were unlikely to have been clinically important.

Several limitations should be outlined in our study. The first limitation is related to the relatively low number of patients included in this study. We a priori calculated our sample size based on a 0.8 power to detect a minimum KSS score delta of 4 points [9], but the number of patients may be limited to detect differences for the other parameters evaluated in this study. The second limitation is related to the relatively short followup of our study to detect aseptic failures as previously described in a recent paper [1]. The third limitation is the potential difficulty to accurately link the subchondral pain at the proximal aspect of the tibia to 
Table 5. Postoperative surgical complications

\begin{tabular}{|c|c|c|c|c|c|c|}
\hline \multirow[t]{2}{*}{ Surgical complication } & \multicolumn{2}{|c|}{$\begin{array}{l}\text { Moderately obese } \\
30<\mathrm{BMI}<35 \mathrm{~kg} / \mathrm{m}^{2}\end{array}$} & \multirow[b]{2}{*}{$\mathrm{p}$ value } & \multicolumn{2}{|c|}{$\begin{array}{l}\text { Severely obese } \\
\text { BMI }>35 \mathrm{~kg} / \mathrm{m}^{2}\end{array}$} & \multirow[b]{2}{*}{$\mathrm{p}$ value } \\
\hline & Stemmed TKA & Standard & & Stemmed TKA & Standard & \\
\hline \multirow[t]{2}{*}{ Wound drainage or delayed healing } & $4(7 \%$ & & NS & $5(8 \%)$ & & NS \\
\hline & $2(7 \%)$ & $2(7 \%)$ & NS & $3(10 \%)$ & $2(7 \%)$ & NS \\
\hline \multirow[t]{2}{*}{ Revision for any reason } & $1(2 \%$ & & NS & $1(2 \%)$ & & NS \\
\hline & $1(3 \%)$ & 0 & NS & 0 & $1(3 \%)$ & NS \\
\hline \multirow[t]{2}{*}{ Revision for aseptic loosening } & 0 & & NS & $1(2 \%)$ & & NS \\
\hline & 0 & 0 & NS & 0 & $1(3 \%)$ & NS \\
\hline \multirow[t]{2}{*}{ Tibial lucencies or lysis } & $1(2 \%$ & & NS & $2(4 \%)$ & & NS \\
\hline & 0 & $1(3 \%)$ & NS & $1(3 \%)$ & $1(3 \%)$ & NS \\
\hline
\end{tabular}

Values are number $(\%)$; BMI = body mass index; NS = nonsignificant.

an overload problem. Finally, we did not compare the patients with obesity with a group of nonobese patients. This cohort needs a longer followup with clinical, radiological, and survivorship analysis to determine the potential role of the stem at longer followup.

No clinically important differences were observed in function and pain between patients with obesity treated with or without a stem. In our series, pain at the proximal aspect (defined as the area between the joint line and the 5 $\mathrm{cm}$ above) of the tibia was analyzed postoperatively. Pain has been evaluated after TKA in patients with obesity but to our knowledge, the proximal tibial pain that we evaluated has not been studied by others [4, 12, 15-17, 23]. In a previous report, obesity was not associated with a higher risk of moderate to severe pain in patients undergoing primary TKA at 2- or 5-year followup [4]. Previously published papers regarding BMI and pain after TKA reported controversial results [6, 14, 17-19, 24]. Most previous studies have examined the association of BMI with summary scores (not pain) [4, 12, 15-17, 23], mostly using the KSS total and objective/subjective scores and most reporting lack of an association, whereas few were positive. In one study, however, analyzing the results of 67 patients undergoing TKA for an association of obesity with pain outcomes [17], BMI of 35 to $40 \mathrm{~kg} / \mathrm{m}^{2}$ was associated with higher pain scores in multivariable-adjusted models that included age, gender, and comorbidities. In our earlier experience [2], pain at the proximal aspect of the tibia was observed for obese women. It was our hypothesis that a stem would limit the effect of the load during gait and consecutively limit the pain. In fact, the abduction moment at heel strike is maximal on the medial aspect of the knee and related to the patient's weight [3]. In patients with obesity, the stem can spread the forces from the metaphysis to the diaphysis, limiting the load and consecutively the pain at the proximal aspect of the tibia [22]. We did not observe any pain at the tip of the stems in this study. All the stems were undersized (the stem diameter was always 10 $\mathrm{mm}$, which is the smallest possible) to avoid any stress shielding. Long stems were used to optimize implant positioning and use the "alignment" potential of the stems in this particular group of patients as described by Vince for revision TKA [26].

We found no difference in terms of general quality-oflife scores among groups and subgroups at a minimum followup of 2 years in our study. A previous study [17] analyzing the SF-36 between 3 and 5 years after TKA in patients with obesity found that patients with obesity had a $13 \%$ lower physical component score for each increase of 1 $\mathrm{kg} / \mathrm{m}^{2}$ of BMI. The authors concluded that there is an inverse correlation between BMI and performing physical activity such as climbing stairs and walking. Patients with a high BMI are more limited than patients with a lower BMI in performing all kinds of physical activities without limitations. The higher the BMI, the more nervous and sad the patient was, and the more difficult it was for the patient to maintain social functioning. Another study did not report such effect of BMI on quality of life [19]. To our knowledge, quality of life in patients with obesity has never been evaluated according to the type of implant used. In our study, the addition of a stem on the tibial component did not confer any advantage in term of quality at 2-year followup.

No difference in terms of mechanical complications and premature revision (defined as revision before 2 years) were found in our study. Abdel et al. [1] recently reported that risk for revision TKA resulting from aseptic tibial component failure was almost two times greater in those with a BMI of $\geq 35 \mathrm{~kg} / \mathrm{m}^{2}$ independently of age and coronal alignment. This article is in accordance with one previous paper [5]. Berend et al. [5] reported a higher risk of tibial component failure for patients with a BMI $>34$ 
$\mathrm{kg} / \mathrm{m}^{2}$. An analysis at longer followup may be interesting to answer the question of the additional fixation. Abdel et al. [1] in their paper suggested additional fixation for patients with obesity using a short cemented stem. In our study, a long stem with metaphyseal fixation was implanted to use both the alignment potential of the stem and the loadsharing potential. However, the stems resulted in no advantage either in terms of alignment or loosening.

In conclusion, although we detected differences in patient-reported outcomes scores favoring implants with stems, the differences were small and unlikely to be clinically important. Because these stems may have disadvantages, perhaps including difficulty of revision, we cannot draw a strong conclusion in support of their use. Patients with osteopenia had somewhat less tibial pain when a stem was used, but this was a secondary analysis and the finding should be interpreted cautiously.

\section{References}

1. Abdel MP, Bonadurer GF, Jennings MT, Hanssen AD. Increased aseptic tibial failures in patients with a BMI $\geq 35$ and wellaligned total knee arthroplasties. J Arthroplasty. 2015;30:21812184.

2. Argenson J-N, Parratte S, Ashour A, Komistek RD, Scuderi GR. Patient-reported outcome correlates with knee function after a single-design mobile-bearing TKA. Clin Orthop Relat Res. 2008;466:2669-2676.

3. Argenson J-NA, Scuderi GR, Komistek RD, Scott WN, Kelly MA, Aubaniac J-M. In vivo kinematic evaluation and design considerations related to high flexion in total knee arthroplasty. $J$ Biomech. 2005;38:277-284.

4. Baker P, Muthumayandi K, Gerrand C, Kleim B, Bettinson K, Deehan D. Influence of body mass index (BMI) on functional improvements at 3 years following total knee replacement: a retrospective cohort study. PloS One. 2013;8:e59079.

5. Berend ME, Ritter MA, Meding JB, Faris PM, Keating EM, Redelman R, Faris GW, Davis KE. Tibial component failure mechanisms in total knee arthroplasty. Clin Orthop Relat Res. 2004;428:26-34.

6. Boeckstyns ME, Backer M. Reliability and validity of the evaluation of pain in patients with total knee replacement. Pain. 1989;38:29-33.

7. Cipriano CA, Brown NM, Della Valle CJ, Moric M, Sporer SM. Intra-operative periprosthetic fractures associated with press fit stems in revision total knee arthroplasty: incidence, management, and outcomes. J Arthroplasty. 2013;28:1310-1313.

8. Clement ND, MacDonald D, Simpson AHRW. The minimal clinically important difference in the Oxford knee score and Short Form 12 score after total knee arthroplasty. Knee Surg Sports Traumatol Arthrosc. 2014;22:1933-1939.

9. Dewan A, Bertolusso R, Karastinos A, Conditt M, Noble PC, Parsley BS. Implant durability and knee function after total knee arthroplasty in the morbidly obese patient. $J$ Arthroplasty. 2009;24:89-94, 94.e1-3.

10. Ewald FC. The Knee Society total knee arthroplasty roentgenographic evaluation and scoring system. Clin Orthop Relat Res. 1989;248:9-12.
11. Insall JN, Dorr LD, Scott RD, Scott WN. Rationale of the Knee Society clinical rating system. Clin Orthop Relat Res. 1989;248:13-14.

12. Issa K, Pivec R, Kapadia BH, Shah T, Harwin SF, Delanois RE, Mont MA. Does obesity affect the outcomes of primary total knee arthroplasty? J Knee Surg. 2013;26:89-94.

13. Kurtz S, Ong K, Lau E, Mowat F, Halpern M. Projections of primary and revision hip and knee arthroplasty in the United States from 2005 to 2030. J Bone Joint Surg Am. 2007;89:780785 .

14. Lifshitz F, Lifshitz JZ. Globesity: the root causes of the obesity epidemic in the USA and now worldwide. Pediatr Endocrinol Rev. 2014;12:17-34.

15. Liljensøe A, Lauersen JO, Søballe K, Mechlenburg I. Overweight preoperatively impairs clinical outcome after knee arthroplasty: a cohort study of 197 patients 3-5 years after surgery. Acta Orthop. 2013;84:392-397.

16. McElroy MJ, Pivec R, Issa K, Harwin SF, Mont MA. The effects of obesity and morbid obesity on outcomes in TKA. J Knee Surg. 2013;26:83-88.

17. Núñez M, Núñez E, Segur JM, Maculé F, Sanchez A, Hernández MV, Vilalta C. Health-related quality of life and costs in patients with osteoarthritis on waiting list for total knee replacement. Osteoarthritis Cartilage. 2007;15:258-265.

18. Ornetti P, Parratte S, Gossec L, Tavernier C, Argenson J-N, Roos EM, Guillemin F, Maillefert JF. Cross-cultural adaptation and validation of the French version of the Knee injury and Osteoarthritis Outcome Score (KOOS) in knee osteoarthritis patients. Osteoarthritis Cartilage. 2008;16:423-428.

19. Papakostidou I, Dailiana ZH, Papapolychroniou T, Liaropoulos L, Zintzaras E, Karachalios TS, Malizos KN. Factors affecting the quality of life after total knee arthroplasties: a prospective study. BMC Musculoskelet Disord. 2012;13:116.

20. Pugely AJ, Martin CT, Gao Y, Belatti DA, Callaghan JJ. Comorbidities in patients undergoing total knee arthroplasty: do they influence hospital costs and length of stay? Clin Orthop Relat Res. 2014;472:3943-3950.

21. Roos EM, Roos HP, Lohmander LS, Ekdahl C, Beynnon BD. Knee Injury and Osteoarthritis Outcome Score (KOOS)-development of a self-administered outcome measure. J Orthop Sports Phys Ther. 1998;28:88-96.

22. Scott CEH, Biant LC. The role of the design of tibial components and stems in knee replacement. $J$ Bone Joint Surg Br. 2012;94:1009-1015.

23. Singh JA, Gabriel SE, Lewallen DG. Higher body mass index is not associated with worse pain outcomes after primary or revision total knee arthroplasty. J Arthroplasty. 2011;26:366-374.e1.

24. Springer BD, Parratte S, Abdel MP. Measured resection versus gap balancing for total knee arthroplasty. Clin Orthop Relat Res. 2014;472:2016-2022.

25. Sturm R, An R. Obesity and economic environments. CA Cancer J Clin. 2014;64:337-350.

26. Vince KG. A step-wise approach to revision TKA. Orthopedics. 2005;28:999-1001.

27. Wang YC, McPherson K, Marsh T, Gortmaker SL, Brown M. Health and economic burden of the projected obesity trends in the USA and the UK. Lancet. 2011;378:815-825.

28. Ware J, Kosinski M, Keller SD. A 12-Item Short-Form Health Survey: construction of scales and preliminary tests of reliability and validity. Med Care. 1996;34:220-233.

29. World Health Organization. Obesity. Available at: http://www. who.int/topics/obesity/en/. Accessed September 30, 2015.

30. World Health Organization. Meeting Report-Osteoporosis. Available at: http://www.who.int/chp/topics/Osteoporosis.pdf. Accessed September 30, 2015. 